\title{
Dental prophylaxis decreases the risk of acute myocardial infarction: a nationwide population-based study in Taiwan
}

This article was published in the following Dove Press journal:

Clinical Interventions in Aging

6 January 2015

Number of times this article has been viewed

\author{
Ya-Ling Lee ${ }^{1,2}$ \\ Hsiao-Yun $\mathrm{Hu}^{2,3}$ \\ Pesus Chou ${ }^{2}$ \\ Dachen $\mathrm{Chu}^{2,4,5}$ \\ 'Department of Dentistry, Taipei \\ City Hospital, ${ }^{2}$ Institute of Public \\ Health and Community Medicine \\ Research Center, National Yang- \\ Ming University, ${ }^{3}$ Department \\ of Education and Research, Taipei \\ City Hospital, ${ }^{4}$ Department of Health \\ Care Management, National \\ Taipei University of Nursing and \\ Health Sciences, ${ }^{5}$ Department \\ of Neurosurgery, Taipei City Hospital, \\ Taipei, Taiwan
}

\begin{abstract}
Purpose: To investigate the association between periodontal disease (PD) and acute myocardial infarction (AMI), and evaluate the effect of dental prophylaxis on the incidence rate (IR) of AMI.
\end{abstract}

Methods: The Longitudinal Health Insurance Database 2000 from the National Health Insurance program was used to identify 511,630 patients with PD and 208,713 without PD during 2000-2010. Subjects with PD were grouped according to treatment (dental prophylaxis, intensive treatment, and PD without treatment). The IRs of AMI during the 10-year follow-up period were compared among groups. Cox regression analysis adjusted for age, sex, socioeconomic status, residential urbanicity, and comorbidities was used to evaluate the effect of PD treatment on the incidence of AMI.

Results: The IR of AMI among subjects without PD was $0.19 \% /$ year. Among those with PD, the IR of AMI was lowest in the dental prophylaxis group ( $0.11 \% /$ year), followed by the intensive treatment $(0.28 \%$ /year) and PD without treatment $(0.31 \% /$ year; $P<0.001)$ groups. Cox regression showed that the hazard ratio (HR) for AMI was significantly lower in the dental prophylaxis group ( $\mathrm{HR}=0.90,95 \%$ confidence interval $=0.86-0.95)$ and higher in the intensive treatment $(\mathrm{HR}=1.09,95 \%$ confidence interval $=1.03-1.15)$ and $\mathrm{PD}$ without treatment $(\mathrm{HR}=1.23,95 \%$ confidence interval $=1.13-1.35$ ) groups than in subjects without PD.

Conclusion: PD is associated with a higher risk of AMI, which can be reduced by dental prophylaxis to maintain periodontal health.

Keywords: periodontal disease, acute myocardial infarction, dental prophylaxis, dental scaling

\section{Introduction}

Coronary heart disease (CHD) is the leading cause of morbidity and mortality worldwide, with a prevalence ranging from $2 \%-20 \% .{ }^{1,2}$ Acute myocardial infarction (AMI) is a CHD-related event that may result in sudden death. The risk factors for CHD include age, male sex, hypertension, diabetes mellitus, dyslipidemia, smoking, and inflammatory diseases, such as periodontal disease (PD). ${ }^{3-6}$

About $20 \%-50 \%$ of the population worldwide has PD. ${ }^{7-9}$ This disease is caused by the accumulation of a specific bacterial biofilm around teeth. The initial presentation is reversible gingivitis, which can be treated after biofilm removal. ${ }^{10-12}$ As PD progresses, destruction of the periodontal connective tissue and alveolar bone ultimately lead to tooth loss. ${ }^{13}$ Increased tooth brushing frequency has been found to reduce the serum concentrations of $\mathrm{C}$-reactive protein and fibrinogen, suggesting that the improvement of periodontal conditions can reduce a patient's systemic inflammatory status. ${ }^{14}$
Correspondence: Dachen Chu Taipei City Hospital Zhongxing Branch, No 145, Zheng Zhou Road, Datong,

Taipei, Taiwan

Tel +8862 25523234 ext 1000

Fax +886225521608

Email DAD57@tpech.gov.tw 
Some previous researchers have concluded that poor periodontal status is associated with an increased risk of CHD..$^{13,15-18}$ Deep periodontal pockets have been found in individuals who have experienced AMI and have been associated with an increased incidence of this event. ${ }^{19-21}$ A larger variation of subgingival anaerobic microflora has also been observed in those who have experienced AMI and is considered to be a potential risk indicator. ${ }^{22,23}$ However, other reports showed no significant relationship between PD and CHD. ${ }^{24,25}$ The relationships of PD and its treatment with the incidence of AMI remain unclear.

A retrospective cohort study was conducted using the Taiwanese National Health Insurance Research Database (NHIRD) to estimate the incidence rates (IRs) of AMI among subjects with PD and different PD treatment groups.

\section{Methods}

This study received full review by the local institutional review board (Taipei City Hospital Institutional Review Board number: TCHIRB-1020705-E). The institutional review board waived the need for written informed consent from study subjects because all potentially patient-identifying information was encrypted.

\section{Data source}

The compulsory, universal National Health Insurance (NHI) program in Taiwan covers up to $99 \%$ of the nation's inhabitants. In conjunction with the NHI Bureau, the National Health Research Institute established the NHIRD to provide useful epidemiological information for basic and clinical research in Taiwan. The National Health Research Institute administers the NHIRD in a manner that ensures all beneficiaries' privacy and confidentiality, and provides access to researchers only upon ethical approval.

For this study, the Longitudinal Health Insurance Database 2000 (LHID 2000) was used. The LHID 2000 is a standardized sample file for research use provided by the National Health Research Institute, and consists of comprehensive use and enrollment information for a randomly selected sample of 1 million NHI beneficiaries, representing approximately $5 \%$ of all enrollees in Taiwan in 2000. A multistage stratified systematic sampling design was used and it was found that there were no statistically significant differences in sex or age between the sample group and all enrollees. The identification of patients in the LHID 2000 is encrypted to protect their privacy, as this database includes information about medical orders, treatment procedures, and medical diagnoses (coded based on the International
Classification of Diseases, 9th Revision, Clinical Modification [ICD-9-CM]).

\section{Study cohort}

The cohort for this retrospective study was drawn from 1 million beneficiaries sampled randomly from all beneficiaries listed in the NHIRD in the year 2000 (ie, the LHID 2000). Only subjects aged $\geq 20$ years were included $(723,024$ beneficiaries; Figure 1). The subjects were included into the PD cohort if they visited an ambulatory care provider due to PD (ICD-9-CM codes 523.0-523.5) during the study period. Patients who developed AMI before PD diagnosis $(n=2,066)$ and individuals of unknown sex $(n=615)$ were excluded. Individuals with no diagnosis of PD from 2000-2010 served as the control group $(n=208,713$; followed for 2,248,618 person-years).

The PD group (ICD-9-CM codes 523.0-523.5) was divided into three treatment groups:

1) Dental prophylaxis ( $n=344,228$; followed for $2,807,865$ person-years): PD patients who only received dental prophylaxis (procedure codes: 91003, 91004) during the following period.

2) Intensive treatment $(n=121,827$; followed for 789,518 person-years): PD patients who received treatments such as subgingival curettage and root planning (procedure codes: 91006-91008) and/or periodontal flap operation (procedure codes: 91009, 91010) and/or tooth extraction (procedure codes: 92013, 92014).

3) PD without treatment ( $n=45,575$; followed for 170,754 person-years): PD patients who received no treatments. Thus, a total of 720,343 subjects followed for 6,016,755 person-years were included in this study. Participants were followed from the cohort entry date (the first date of an ambulatory care visit due to PD for the PD group and January 1, 2000 for the control group) until the date of hospitalization due to AMI (ICD-9-CM codes 410-412), death, or end of the study period (December 31, 2010).

The socioeconomic status variable had five categories. People with a well-defined monthly payroll were classified into three categories: $=\mathrm{NT} \$ 40,000$, NT $\$ 20,000-\$ 39,999$, and $<$ NT\$20,000 (NT\$: New Taiwan dollars; US\$1 is approximately worth NT\$30). People without a welldefined monthly wage could either enroll through unions or associations, such as farmers' associations, or through local government offices. Those who enrolled through local government offices included self-employed, retirees, corner store owners, or low-income people. People without a welldefined monthly payroll were categorized into two groups: 


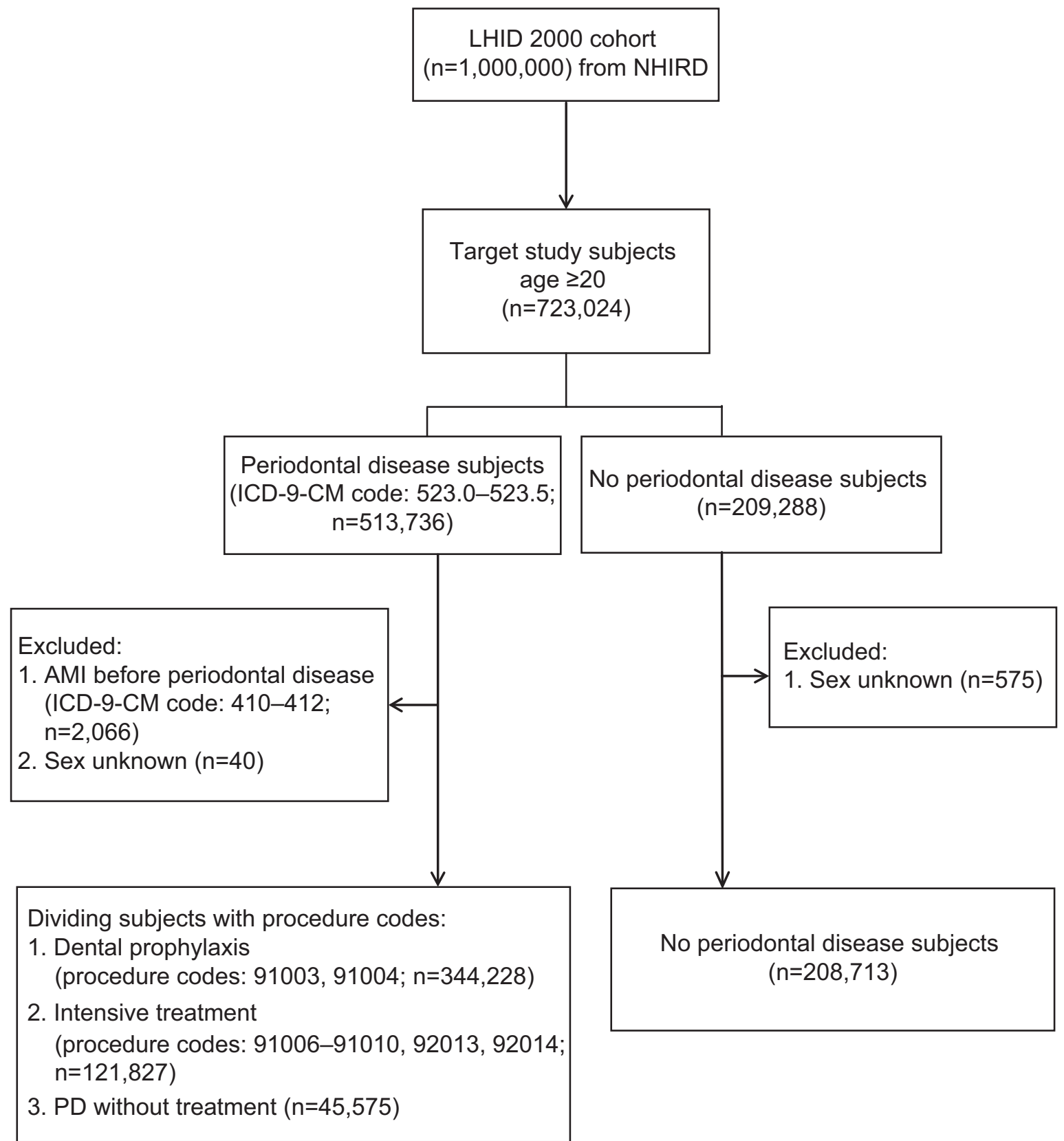

Figure I Selection of study patients.

Abbreviations: AMI, acute myocardial infarction; ICD-9-CM, International Classification of Diseases, 9th Revision, Clinical Modification; LHID, Longitudinal Health Insurance Database; NHIRD, National Health Insurance Research Database; PD, periodontal disease.

union or association members and people enrolled in local government offices.

The residential urbanicity was classified into three categories: urban classification for metropolitan cities; suburban classification for all other cities and counties; and rural classification for all townships and rural areas.

In the analysis of AMI comorbidities, including atrial fibrillation (ICD-9-CM code 437.3), diabetes (ICD-9-CM code 250), hypertension (ICD-9-CM codes 401-405), dyslipidemia (ICD-9-CM code 272), chronic kidney disease
(ICD-9-CM code 585), and peripheral vascular disease (ICD-9-CM codes 440.2, 440.3, 440.9, 443, 444.21, 444.22), only subjects with more than three outpatient visits during the study period were included to increase the validity of diagnoses in the administrative data set.

\section{Statistical methods}

Statistical analyses were performed using the $\mathrm{SAS}^{\circledR}$ statistical package (version 9.2; SAS Institute, Cary, NC, USA). The IRs of AMI among patients with PD and control 
subjects were compared. The $\chi^{2}$ test was used for parametric categorical data. A $P$-value of less than 0.05 was considered significant. A Cox proportional hazards model was used to calculate hazard ratios (HRs) and 95\% confidence intervals (CIs) to determine whether PD is a risk factor for the development of AMI. This model was adjusted for age, sex, socioeconomic status, residential urbanicity, PD treatment, and comorbidities (atrial fibrillation, diabetes mellitus, hypertension, dyslipidemia, chronic kidney disease, and peripheral vascular disease).

\section{Results}

A total of 10,046 patients developed AMI during the follow-up period $(\mathrm{IR}=0.17 \% /$ year; Table 1$)$. The IR of AMI increased with age from $0.03 \% /$ year among subjects aged 20-44 years to $0.24 \%$ and $0.61 \% /$ year among those aged

Table I Univariate analysis of factors affecting the incidence of acute myocardial infarction

\begin{tabular}{|c|c|c|c|c|c|}
\hline Variables & $\begin{array}{l}\text { Total } \\
\text { (n) }\end{array}$ & $\begin{array}{l}\text { AMI } \\
(n)\end{array}$ & $\begin{array}{l}\text { Follow-up } \\
\text { (person-years) }\end{array}$ & $\begin{array}{l}\text { IR } \\
\text { (\%/year) }\end{array}$ & $\begin{array}{l}\chi^{2} \text { test } \\
(P \text {-value })\end{array}$ \\
\hline Total & 720,343 & 10,046 & $6,016,755$ & 0.17 & \\
\hline Age at baseline & & & & & $<0.001$ \\
\hline 20-44 years & 436,383 & 1,032 & $3,622,234$ & 0.03 & \\
\hline $45-64$ years & 186,875 & 3,633 & $\mathrm{I}, 506,826$ & 0.24 & \\
\hline$\geq 65$ years & 97,085 & $5,38 I$ & 887,695 & 0.61 & \\
\hline Sex & & & & & $<0.001$ \\
\hline Female & 352,249 & 3,689 & $2,927,932$ & 0.13 & \\
\hline Male & 368,094 & 6,357 & $3,088,823$ & 0.21 & \\
\hline Socioeconomic status & & & & & $<0.001$ \\
\hline$<$ NT $\$ 20,000$ & 194,532 & $\mathrm{I}, 743$ & $\mathrm{I}, 777,477$ & 0.10 & \\
\hline NT $\$ 20,000-39,999$ & 179,369 & $\mathrm{I}, 552$ & $\mathrm{I}, 397,6 \mathrm{II}$ & 0.11 & \\
\hline$\geq \mathrm{NT} \$ 40,000$ & 128,113 & $\mathrm{I}, 463$ & $1,020,913$ & 0.14 & \\
\hline Union/association member & 103,075 & 2,813 & 870,662 & 0.32 & \\
\hline Local government enrollees & 115,254 & 2,475 & 950,093 & 0.26 & \\
\hline Residential urbanicity & & & & & $<0.001$ \\
\hline Urban & 434,975 & 5,308 & $3,594,699$ & 0.15 & \\
\hline Suburban & 220,457 & 3,320 & $1,866,215$ & 0.18 & \\
\hline Rural & 64,911 & 1,418 & 555,841 & 0.26 & \\
\hline Periodontal disease & & & & & $<0.001$ \\
\hline No PD & 208,713 & 4,327 & $2,248,618$ & 0.19 & \\
\hline Dental prophylaxis & 344,228 & 2,952 & $2,807,865$ & 0.11 & \\
\hline Intensive treatment & $|2|, 827$ & 2,233 & 789,518 & 0.28 & \\
\hline PD without treatment & 45,575 & 534 & 170,754 & 0.31 & \\
\hline \multicolumn{6}{|l|}{ Comorbidity } \\
\hline Atrial fibrillation & & & & & $<0.001$ \\
\hline No & $7 \mid 4,085$ & 9,594 & $5,965,27 \mid$ & 0.16 & \\
\hline Yes & 6,258 & 452 & 51,484 & 0.88 & \\
\hline Diabetes & & & & & $<0.001$ \\
\hline No & 638,060 & 6,406 & $5,355,794$ & 0.12 & \\
\hline Yes & 82,283 & 3,640 & 660,962 & 0.55 & \\
\hline Hypertension & & & & & $<0.001$ \\
\hline No & 544,877 & 3,072 & $4,603,550$ & 0.07 & \\
\hline Yes & 175,466 & 6,974 & $\mathrm{I}, 4 \mid 3,206$ & 0.49 & \\
\hline Dyslipidemia & & & & & $<0.001$ \\
\hline No & 605,948 & 6,755 & $5,117,645$ & 0.13 & \\
\hline Yes & 114,395 & 3,291 & 899,110 & 0.37 & \\
\hline CKD & & & & & $<0.001$ \\
\hline No & 708,023 & 9,158 & $5,914,168$ & 0.15 & \\
\hline Yes & 12,320 & 888 & 102,587 & 0.87 & \\
\hline PVD & & & & & $<0.001$ \\
\hline No & 706,158 & 9,452 & $5,902,939$ & 0.16 & \\
\hline Yes & 14,185 & 594 & 113,816 & 0.52 & \\
\hline
\end{tabular}

Note: US\$I is approximately worth NT\$30.

Abbreviations: AMI, acute myocardial infarction; CKD, chronic kidney disease; IR, incidence rate; NT\$, New Taiwan dollar; PD, periodontal disease; PVD, peripheral vascular disease. 
45-64 years and $>65$ years, respectively $(P<0.001)$. The IR of AMI was higher among men than women $(0.21 \%$ versus $0.13 \% /$ year) and was significantly higher among subjects with atrial fibrillation ( $0.88 \%$ /year), diabetes mellitus $(0.55 \%$ / year), hypertension $(0.49 \%$ /year $)$, dyslipidemia $(0.37 \%$ / year), chronic kidney disease $(0.87 \%$ year $)$, and peripheral vascular disease $(0.52 \%$ /year $)$ than people without these comorbidities (all $P<0.001$ ).

A total of 4,327 people without PD developed AMI (IR $=0.19 \% /$ year). Among those with PD, the IR of AMI was lowest in the dental prophylaxis group $(0.11 \% /$ year $)$ and highest in the PD without treatment group $(0.31 \% /$ year; $P<0.001)$.

When comparing IRs of AMI after being stratified by age, sex, socioeconomic status, residential urbanicity, and comorbidity variables (Table 2), the lowest IR of the PD population always appeared in the dental prophylaxis group, followed by the intensive treatment group and PD without treatment group ( $P<0.001$ or $P=0.013$ for the trend test).

Cox regression analysis adjusted for age, sex, socioeconomic status, residential urbanicity, and comorbidities showed that the HR of AMI was significantly lower in the dental prophylaxis group $(\mathrm{HR}=0.90,95 \% \mathrm{CI}=0.86-0.95)$ and higher in the intensive treatment $(\mathrm{HR}=1.09,95 \%$ $\mathrm{CI}=1.03-1.15)$ and $\mathrm{PD}$ without treatment (HR $=1.23,95 \%$ $\mathrm{CI}=1.13-1.35)$ groups than among subjects with no PD (Table 3). The $r^{2}$ correlate of the Cox regression model was $2.38 \%$.

\section{Discussion}

This is the first nationwide, population-based study to examine the strength of association between periodontal treatment and the incidence of AMI. The results of this study demonstrated that PD is a significant risk factor for AMI, and that dental prophylaxis protects against AMI development.

The findings support the concept that inflammatory diseases such as PD may play a role in the pathogenesis of AMI. The association of PD with the prevalence of CHD suggests that inflammation may be a potential mechanism involved in the regulation of the atherosclerotic process. ${ }^{26,27}$ PD may induce immune cells to secrete the inflammatory cytokines thromboxane A2, interleukin $1 \beta$, prostaglandin $\mathrm{E} 2$, and tumor necrosis factor $\alpha$, which trigger and exacerbate atherogenetic and thromboembolic processes, resulting in CHD. ${ }^{26,28-30}$ Poor periodontal condition was also reported to be associated significantly with an increased concentration of C-reactive protein, ${ }^{31-34}$ a well-studied inflammatory marker and an independent predictor of CHD. ${ }^{35,36}$ In addition to circulating inflammatory factors, oral microbial organelles circulating in the blood have been proposed to lead to the increased incorporation of PD pathogens in atherosclerotic plaque. ${ }^{26,37}$ The attached PD pathogens can then adhere to vascular cells, inducing vascular infection and atherothrombosis and eventually causing AMI ${ }^{38}$

The HRs among the different PD treatment groups were statistically significantly different. Sometimes this can be due to the very huge sample size used. However, the authors believe that the difference of HR among PD treatment groups had clinical significance. Other different approaches to PD-related conditions also showed a similar finding in the association with AMI. The National Health and Nutrition Examination Survey III cohort study found that patients with severe PD had a four-fold higher risk of myocardial infarction than those without PD. ${ }^{39}$ Infections of dental origin have also been documented in patients experiencing myocardial infarction. ${ }^{40}$ Periodontal pocket depth has been reported to be associated with the IR of AMI. ${ }^{19,20}$ Tooth loss, an indicator of PD history, was significantly related to carotid intima-media thickness, a strong predictor of myocardial infarction and stroke. ${ }^{37,41}$ Treatment of PD resulting in a beneficial effect on vascular diseases such as AMI and stroke was also reported. ${ }^{42-44}$ The results of a cross-sectional randomized clinical study suggested that nonintensive, Phase I periodontal therapy decreased serum immunoglobulin $\mathrm{G}$ and immunoglobulin M levels in patients who developed AMI. ${ }^{42}$ A 7-year cohort study by Chen et al showed that frequent tooth scaling reduced the IR and risk of AMI among subjects aged $>50$ years..$^{43}$ In a previous study, it was found that dental prophylaxis reduced the risk of ischemic stroke in subjects with PD, especially those aged 20-44 years. ${ }^{44}$

Several limitations of this study must be considered. First, the use of administrative data and the retrospective design may have resulted in bias with respect to diagnoses. A further concern is the nonresponder bias/selection bias. Although the NHI program in Taiwan covered up to $99 \%$ of the nation's inhabitants and provides free dental check-ups and prophylaxis twice a year to promote the prevention of PD, some PD patients may not be included in this NHI database because they did not have health insurance or did not seek treatment or check-up. However, the NHI Bureau routinely samples patient charts in different medical centers to validate database quality and minimize miscoding or misclassification. In addition, patients with PD were identified using both ICD-9-CM diagnostic codes and PD treatment codes in this study to minimize classification errors. Only patients with more than three outpatient visits were included in the analysis 


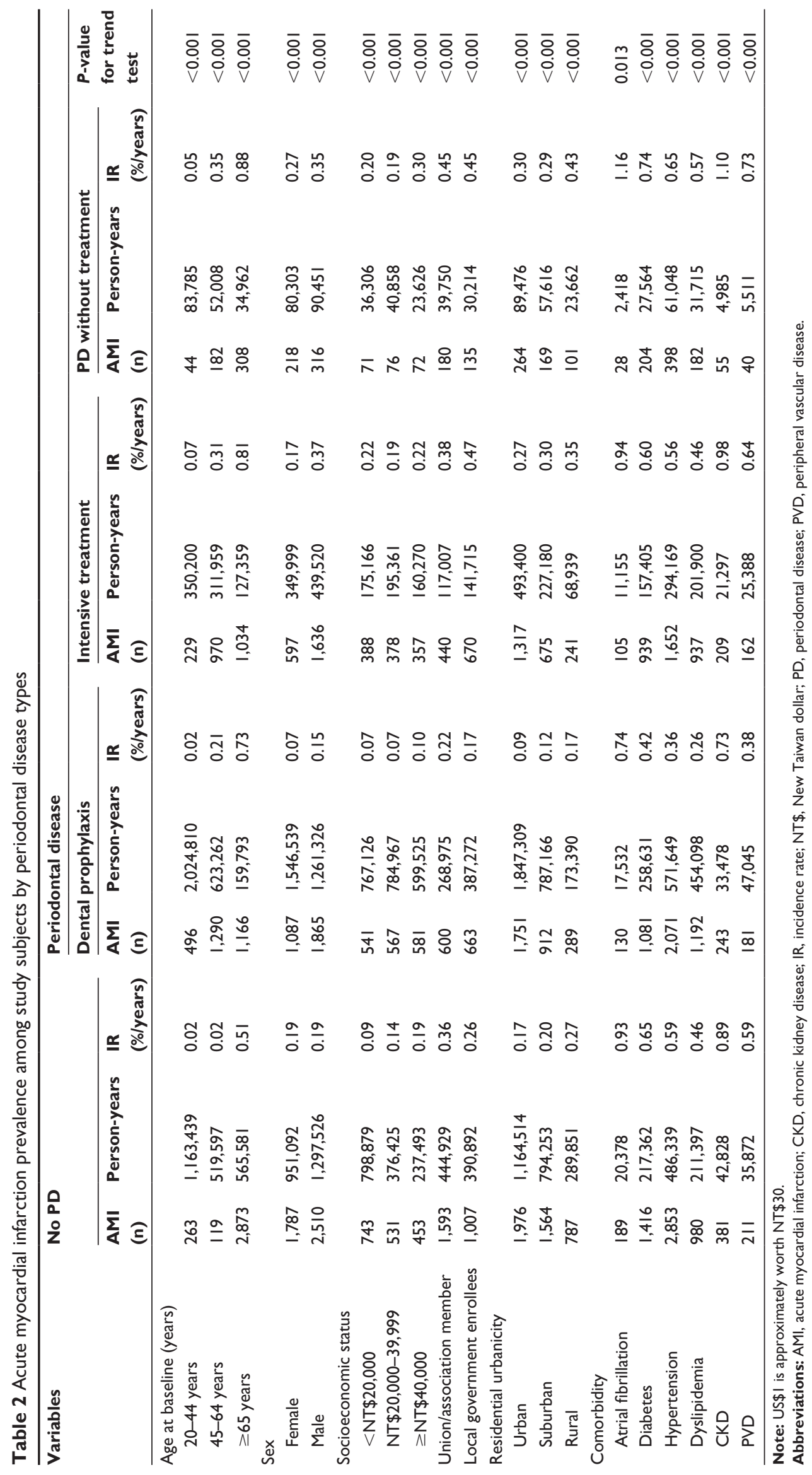


Table 3 Results of Cox regression analysis conducted to identify predictors of acute myocardial infarction development

\begin{tabular}{|c|c|c|}
\hline Variables & HR & $95 \% \mathrm{Cl}$ \\
\hline \multicolumn{3}{|l|}{ Age at baseline } \\
\hline $20-44$ years & 1.00 & \\
\hline $45-64$ years & 4.72 & $4.39-5.08$ \\
\hline$\geq 65$ years & 9.93 & $9.21-10.7 \mid$ \\
\hline \multicolumn{3}{|l|}{ Sex } \\
\hline Female & 1.00 & \\
\hline Male & 1.66 & $1.59-1.73$ \\
\hline \multicolumn{3}{|l|}{ Socioeconomic status } \\
\hline$<\mathrm{NT} \$ 20,000$ & 1.00 & \\
\hline NT\$20,000-39,999 & 0.97 & $0.91-1.04$ \\
\hline$\geq \mathrm{NT} \$ 40,000$ & 0.98 & $0.91-1.05$ \\
\hline Union/association member & 1.10 & $1.02-1.18$ \\
\hline Local government enrollees & 1.17 & $1.10-1.25$ \\
\hline \multicolumn{3}{|l|}{ Residential urbanicity } \\
\hline Urban & 1.00 & \\
\hline Suburban & 1.01 & $0.96-1.06$ \\
\hline Rural & 1.02 & $0.95-1.09$ \\
\hline \multicolumn{3}{|l|}{ Periodontal disease } \\
\hline No PD & 1.00 & \\
\hline Dental prophylaxis & 0.90 & $0.86-0.95$ \\
\hline Intensive treatment & 1.09 & $1.03-1.15$ \\
\hline PD without treatment & 1.23 & $1.13-1.35$ \\
\hline \multicolumn{3}{|l|}{ Comorbidity } \\
\hline Atrial fibrillation & 1.52 & $1.38-1.67$ \\
\hline Diabetes & 1.62 & $1.55-1.69$ \\
\hline Hypertension & 2.63 & $2.50-2.76$ \\
\hline Dyslipidemia & 1.09 & $1.04-1.14$ \\
\hline CKD & 1.60 & $1.49-1.72$ \\
\hline PVD & 1.01 & $0.93-1.10$ \\
\hline
\end{tabular}

Note: US\$I is approximately worth NT\$30.

Abbreviations: $\mathrm{Cl}$, confidence interval; $\mathrm{CKD}$, chronic kidney disease; $\mathrm{HR}$, hazard ratio; NT\$, New Taiwan dollar; PD, periodontal disease; PVD, peripheral vascular disease.

of AMI and comorbidities to reduce nondifferential misclassification bias. Second, the lack of information provided by the NHIRD on other risk factors for PD and AMI, such as education, family history, body mass index, and smoking status, could reduce the feasibility and accuracy of the interpretation of analytical outcomes. However, several recent studies have indicated that the significant associations of PD with AMI and recurrent cardiovascular events in patients developing myocardial infarction are independent of smoking status. ${ }^{34,45-47} \mathrm{PD}$ has also been demonstrated to contribute to elevated C-reactive protein levels in nondiabetic, nonsmoking patients who have experienced AMI. ${ }^{48}$

\section{Conclusion}

The current study demonstrated that PD is correlated with the risk of AMI, and that dental prophylaxis can significantly reduce the IR of AMI. Patients who receive regular prophylactic dental treatment are more likely to have healthier periodontal conditions and less likely to have systemic chronic inflammatory reactions, resulting in a lower IR of AMI.

\section{Disclosure}

The authors report no conflicts of interest in this work. All authors take responsibility for all aspects of the reliability and freedom from bias of the data presented and their discussed interpretation.

\section{References}

1. Roger VL, Go AS, Lloyd-Jones DM, et al. Heart disease and stroke statistics - 2012 update: a report from the American Heart Association. Circulation. 2012;125(1):e2-e220.

2. Management of stable angina pectoris. Recommendations of the Task Force of the European Society of Cardiology. Eur Heart J. 1997;18(3): 394-413.

3. Greenland P, Knoll MD, Stamler J, et al. Major risk factors as antecedents of fatal and nonfatal coronary heart disease events. JAMA. 2003; 290(7):891-897.

4. Kiechl S, Egger G, Mayr M, et al. Chronic infections and the risk of carotid atherosclerosis: prospective results from a large population study. Circulation. 2001;103(8):1064-1070.

5. Dietrich T, Jimenez M, Krall Kaye EA, Vokonas PS, Garcia RI. Agedependent associations between chronic periodontitis/edentulism and risk of coronary heart disease. Circulation. 2008;117(13):1668-1674.

6. Sanz M, D'Aiuto F, Deanfield J, Fernandez-Aviles F. European workshop in periodontal health and cardiovascular disease-scientific evidence on the association between periodontal and cardiovascular diseases: a review of the literature. Eur Heart J Suppl. 2010;12(Suppl B):B3-B12.

7. Albandar JM, Rams TE. Global epidemiology of periodontal diseases: an overview. Periodontol 2000. 2002;29:7-10.

8. Dye BA, Tan S, Smith V, et al. Trends in oral health status: United States, 1988-1994 and 1999-2004. Vital Health Stat 11. 2007;248:1-92.

9. Albandar JM. Underestimation of periodontitis in NHANES surveys. J Periodontol. 2011;82(3):337-341.

10. Petersen PE, Ogawa H. Strengthening the prevention of periodontal disease: the WHO approach. J Periodontol. 2005;76(12):2187-2193.

11. Socransky S, Haffajee A. Microbiology of Periodontal Disease: introduction. Periodontology. 2005;38:9-12.

12. Paster BJ, Boches SK, Galvin JL, et al. Bacterial diversity in human subgingival plaque. J Bacteriol. 2001;183(12):3770-3783.

13. Pihlstrom BL, Michalowicz BS, Johnson NW. Periodontal diseases. Lancet. 2005;366(9499):1809-1820.

14. de Oliveira C, Watt R, Hamer M. Toothbrushing, inflammation, and risk of cardiovascular disease: results from Scottish Health Survey. BMJ. 2010;340:c2451.

15. Loesche WJ, Schork A, Terpenning MS, Chen YM, Kerr C, Dominguez BL. The relationship between dental disease and cerebral vascular accident in elderly United States veterans. Ann Periodontol. 1998;3(1):161-174.

16. Wu T, Trevisan M, Genco RJ, Dorn JP, Falkner KL, Sempos CT. Periodontal disease and risk of cerebrovascular disease: the first National Health and Nutrition Examination Survey and its follow-up study. Arch Intern Med. 2000;160(18):2749-2755.

17. Bahekar AA, Singh S, Saha S, Molnar J, Arora R. The prevalence and incidence of coronary heart disease is significantly increased in periodontitis: a meta-analysis. Am Heart J. 2007;154(5):830-837.

18. Humphrey LL, Fu R, Buckley DI, Freeman M, Helfand M. Periodontal disease and coronary heart disease incidence: a systematic review and meta-analysis. J Gen Intern Med. 2008;23(12):2079-2086.

19. Emingil G, Buduneli E, Aliyev A, Akilli A, Atilla G. Association between periodontal disease and acute myocardial infarction. J Periodontol. 2000;71(12):1882-1886. 
20. Geerts SO, Legrand V, Charpentier J, Albert A, Rompen EH. Further evidence of the association between periodontal conditions and coronary artery disease. J Periodontol. 2004;75(9):1274-1280.

21. Andriankaja OM, Genco RJ, Dorn J, et al. The use of different measurements and definitions of periodontal disease in the study of the association between periodontal disease and risk of myocardial infarction. J Periodontol. 2006;77(6):1067-1073.

22. Dogan B, Buduneli E, Emingil G, et al. Characteristics of periodontal microflora in acute myocardial infarction. J Periodontol. 2005; 76(5):740-748.

23. Stein JM, Kuch B, Conrads G, et al. Clinical periodontal and microbiologic parameters in patients with acute myocardial infarction. J Periodontol. 2009;80(10):1581-1589.

24. Hujoel PP, Drangsholt M, Spiekerman C, DeRouen TA. Periodontal disease and coronary heart disease risk. JAMA. 2000;284(11): 1406-1410.

25. Howell TH, Ridker PM, Ajani UA, Hennekens CH, Christen WG. Periodontal disease and risk of subsequent cardiovascular disease in U.S. male physicians. J Am Coll Cardiol. 2001;37(2):445-450.

26. Lockhart PB, Bolger AF, Papapanou PN, et al. Periodontal disease and atherosclerotic vascular disease: does the evidence support an independent association? A scientific statement from the American Heart Association. Circulation. 2012;125(20):2520-2544.

27. Scannapieco FA, Bush RB, Paju S. Associations between periodontal disease and risk for atherosclerosis, cardiovascular disease, and stroke. A systematic review. Ann Periodontol. 2003;8(1):38-53.

28. Stein JM, Smeets R, Reichert S, et al. The role of the composite interleukin-1 genotype in the association between periodontitis and acute myocardial infarction. J Periodontol. 2009;80(7):1095-1102.

29. Lowe GD. The relationship between infection, inflammation, and cardiovascular disease: an overview. Ann Periodontol. 2001;6(1):1-8.

30. Mustapha IZ, Debrey S, Oladubu M, Ugarte R. Markers of systemic bacterial exposure in periodontal disease and cardiovascular disease risk: a systematic review and meta-analysis. J Periodontol. 2007; 78(12):2289-2302.

31. Wu T, Trevisan M, Genco RJ, Falkner KL, Dorn JP, Sempos CT. Examination of the relation between periodontal health status and cardiovascular risk factors: serum total and high density lipoprotein cholesterol, C-reactive protein, and plasma fibrinogen. Am J Epidemiol. 2000;151(3):273-282.

32. Ridker PM, Silvertown JD. Inflammation, C-reactive protein, and atherothrombosis. J Periodontol. 2008;79(8 Suppl):1544-1551.

33. Noack B, Genco RJ, Trevisan M, Grossi S, Zambon JJ, De Nardin E. Periodontal infections contribute to elevated systemic $\mathrm{C}$-reactive protein level. J Periodontol. 2001;72(9):1221-1227.

34. Deliargyris EN, Madianos PN, Kadoma W, et al. Periodontal disease in patients with acute myocardial infarction: prevalence and contribution to elevated C-reactive protein levels. Am Heart J. 2004;147(6): 1005-1009.
35. Yeboah J, McClelland RL, Polonsky TS, et al. Comparison of novel risk markers for improvement in cardiovascular risk assessment in intermediate-risk individuals. JAMA. 2012;308(8):788-795.

36. Di Napoli M, Schwaninger M, Cappelli R, et al. Evaluation of C-reactive protein measurement for assessing the risk and prognosis in ischemic stroke: a statement for health care professionals from the CRP Pooling Project members. Stroke. 2005;36(6):1316-1329.

37. Desvarieux M, Demmer RT, Rundek T, et al. Periodontal microbiota and carotid intima-media thickness: the Oral Infections and Vascular Disease Epidemiology Study (INVEST). Circulation. 2005;111(5):576-582.

38. Dorn BR, Dunn WA Jr, Progulske-Fox A. Invasion of human coronary artery cells by periodontal pathogens. Infect Immun. 1999;67(11): 5792-5798.

39. Arbes SJ Jr, Slade GD, Beck JD. Association between extent of periodontal attachment loss and self-reported history of heart attack: an analysis of NHANES III data. J Dent Res. 1999;78(12):1777-1782.

40. Willershausen B, Kasaj A, Willershausen I, et al. Association between chronic dental infection and acute myocardial infarction. J Endod. 2009; 35(5):626-630.

41. Desvarieux M, Demmer RT, Rundek T, et al. Relationship between periodontal disease, tooth loss, and carotid artery plaque: the Oral Infections and Vascular Disease Epidemiology Study (INVEST). Stroke. 2003;34(9):2120-2125

42. Gunupati S, Chava VK, Krishna BP. Effect of Phase I periodontal therapy on anti-cardiolipin antibodies in patients with acute myocardial infarction associated with chronic periodontitis. J Periodontol. 2011; 82(12):1657-1664

43. Chen ZY, Chiang CH, Huang CC, et al. The association of tooth scaling and decreased cardiovascular disease: a nationwide population-based study. Am J Med. 2012;125(6):568-575.

44. Lee YL, Hu HY, Huang N, Hwang DK, Chou P, Chu D. Dental prophylaxis and periodontal treatment are protective factors to ischemic stroke. Stroke. 2013;44(4):1026-1030.

45. Andriankaja OM, Genco RJ, Dorn J, et al. Periodontal disease and risk of myocardial infarction: the role of gender and smoking. Eur J Epidemiol. 2007;22(10):699-705.

46. Mattila KJ, Nieminen MS, Valtonen VV, et al. Association between dental health and acute myocardial infarction. BMJ. 1989; 298(6676): 779-781.

47. Dorn JM, Genco RJ, Grossi SG, et al. Periodontal disease and recurrent cardiovascular events in survivors of myocardial infarction (MI): the Western New York Acute MI Study. J Periodontol. 2010;81(4): 502-511.

48. Kodovazenitis G, Pitsavos C, Papadimitriou L, et al. Periodontal disease is associated with higher levels of C-reactive protein in non-diabetic, non-smoking acute myocardial infarction patients. J Dent. 2011;39(12): 849-854.
Clinical Interventions in Aging

\section{Publish your work in this journal}

Clinical Interventions in Aging is an international, peer-reviewed journal focusing on evidence-based reports on the value or lack thereof of treatments intended to prevent or delay the onset of maladaptive correlates of aging in human beings. This journal is indexed on PubMed Central, MedLine,

\section{Dovepress}

CAS, Scopus and the Elsevier Bibliographic databases. The manuscript management system is completely online and includes a very quick and fair peer-review system, which is all easy to use. Visit http://www.dovepress. com/testimonials.php to read real quotes from published authors. 